\title{
A determinação cristológica do ser humano
}

Paulo Cezar Costa

\section{Resumo}

Para a Igreja Católica, existe uma intrínseca relação entre a criação e a encarnação. No centro dessa relação está Jesus Cristo, Novo Adão e plenitude da revelação, no qual o ser humano é resgatado e encontra a plena realização do seu ser criado à imagem e semelhança de Deus. Assim, a salvação acontece pela determinação cristológica de todo o ser humano e se compreende o alcance do mistério do Verbo Encarnado.

Palavras-chave: Jesus Cristo, Religiões, Salvação, Ser humano.

\section{Abstract}

For the Catholic Church, there is an intrinsic relationship between creation and incarnation. At the center of this relationship is Jesus Christ, New Adam and the fullness of revelation, in which the humanity is rescued and finds full realization of his being created in the image and likeness of God. Thus, the salvation comes by the christological determination of every human being and understands the scope of the mystery of the Incarnate Logos.

Keywords: Jesus Christ, Human Being, Religions, Salvation 
Estamos celebrando os 50 anos da proclamação do Concilio Vaticano II pelo para João XXIII. O Concilio inaugurou um olhar novo da Igreja Católica para as outras religiões. Esta perspectiva se encontra expressa no II capítulo da constituição sobre a Igreja: Lúmen Gentium e na Declaração Nostra Aetate. $\mathrm{Na}$ nossa reflexão partir-se-á da tese de que há uma relação intrínseca entre criação e encarnação, entre a imagem de Deus, que o ser humano foi criado e Cristo, imagem do Deus invisível. Pretende-se assim, mostrar a centralidade da cristologia na abordagem da salvação nas outras religiões, mediante a determinação cristológica do ser humano.

A Constituição Pastoral Gaudium et Spes no n. 22 afirma que o mistério do homem encontra o seu sentido no mistério do Verbo encarnado: $\mathrm{Na}$ realidade o mistério do homem só se torna claro verdadeiramente no mistério do Verbo encarnado. Com efeito, Adão o primeiro homem era figura daquele que haveria de vir, isto é, de Cristo Senhor. Novo Adão, na mesma revelação do mistério do Pai e do seu amor, Cristo manifesta plenamente o homem ao próprio homem e lhe descobre a sua altíssima vocação.

\section{Cristo, mediador da criação}

A reflexão bíblica do Novo Testamento, principalmente, Paulo e João, situa o primado de Cristo no plano da criação e da salvação. Em 1Cor 8, 5-6, Paulo diz: “...existe um só Deus, o Pai de quem tudo procede (exhou ta panta) e para quem nós somos e um só Senhor, Jesus Cristo, por quem tudo existe (di hou tà pánta) e por quem nós somos.... O Filho é apresentado aqui como mediador da criação. O ser e o ser salvo não podem proceder de dois princípios distintos, mas de um único. Este papel de mediador não é realizado autonomamente por Cristo, mas na dependência daquele de quem tudo procede ${ }^{1}$. Também no hino da epístola aos Colossenses (Col 1, 15-18) Cristo é apresentado como primogênito de toda a criação, porque Nele tudo foi criado e como causa da criação: tudo foi criado por Ele e para Ele. Franz Mussner comenta: “... o mundo foi criado "para ele", enquanto Cristo é a meta escondida e graciosa da criação e sua dinâmica, a causa finalis-sobrenatural de todo ser" ${ }^{2}$. Também o prólogo de João proclama a função mediadora do Logos na criação: Tudo foi feito por meio dele e sem ele nada foi feito (Jo 1, 3). O mesmo Logos, mediador da criação, é aquele que trás luz e vida.

\footnotetext{
${ }^{1}$ J. L. Ruiz de la Peña, Teologia da Criação, Edições loyola, São Paulo, 1989, p. 58-59.

${ }^{2}$ F. Mussner, "Criação em Cristo", in Mysterium Salutis, II/2, Editora Vozes, Petrópolis, 1972, p. 53.
} 
Criação e redenção nesta perspectiva não se separam ${ }^{3}$. Assim, nos hinos prépaulinos e no prólogo joaneu criação e salvação estão estreitamente ordenadas uma para a outra e isto, em Cristo, mediador da criação, que simultaneamente é aquele "para quem" o universo foi criado ${ }^{4}$.

\section{Cristo, Novo Adão}

Para transcrever o papel único e universal de Jesus Cristo, Paulo usa o recurso da tipologia bíblica de Adão como se desenvolveu no ambiente apocalíptico. Esta lhe permite de fundir juntos a linha messiânica a ação criadora de Deus que abraça todo o gênero humano. Na primeira epístola aos Coríntios, no contexto da ressurreição dos mortos, A fé em Jesus ressuscitado, Paulo diz: "Mas não! Cristo ressuscitou dos mortos, primícias dos que adormeceram" (1Cor 15,20). Com a expressão "primícias dos que adormeceram», estabelece-se uma oposição entre o papel negativo de Adão e aquele positivo de Cristo: "Com efeito, visto que a morte veio por um homem, também por um homem vem a ressurreição dos mortos. Pois, assim como todos morrem em Adão, em Cristo todos receberão a vida" (1Cor 15,21-22). Recorrendo ao princípio da solidariedade antropológica universal, representada na história bíblica pela figura de "Adão", Paulo afirma a eficácia salvífico universal de Cristo ressuscitado.

$\mathrm{Na}$ segunda parte do mesmo capítulo, Paulo retoma o confronto entre Adão e Cristo para responder à questão sobre a modalidade da ressurreição dos corpos. Na conclusão de uma série de oposições entre o "corpo" que si semeia na terra com a morte e aquele que ressuscita, Paulo observa que "se há um corpo psíquico, há também um corpo espiritual, pneumatiko,n” (1Cor $15,44 b)$. Neste ponto ele introduz o paralelo entre Adão e Cristo sobre a base de uma leitura midrashica de Gn 2,7: "Assim está escrito: o primeiro homem, Adão, foi feito alma vivente; o último Adão tornou-se espírito que dá a vida... o primeiro homem, tirado da terra, é terrestre. O segundo homem vem do céu" (1Cor 15,45.47). Do paralelo, Paulo tira a conseqüência que todos os seres humanos, solidários na morte com o primeiro Adão, aquele terrestre, serão também solidários pela ressurreição e a vida com o segundo homem, aquele celeste, isto é, com Cristo ressuscitado. A força da argumentação de Paulo não depende da hermenêutica do texto bíblico ou da idealização da figura de Adão, mas da fé cristã que proclama Jesus Cristo ressuscitado fonte do Espírito, que é garantia de vida plena e definitiva ( $\mathrm{Rm} 1,3 ; 2$ Cor 3,17).

\footnotetext{
${ }^{3}$ Esta perspectiva que combina criação e redenção já se encontra presente no Antigo Testamento.

${ }^{4}$ F. Mussner, "Criação em Cristo", 56.
} 
O idêntico princípio de solidariedade salvífico universal vem utilizado no capítulo quinto de Romanos. Aqui, à mediação negativa do único homem, Adão, que introduziu no mundo o pecado e com o pecado a morte, se contrapõe a mediação positiva para a ressurreição e a vida eterna do único homem Jesus Cristo (Rm 5,12-19). Em termos positivos se afirma que Adão é tu,poj( prefiguração «daquele que devia vir» $(\mathrm{Rm} 5,14)$. Na série das antíteses, se coloca em evidência não só a universalidade das duas linhas de solidariedade e de mediação, mas sobretudo a maior e superabundante eficácia da linha de solidariedade positiva inaugurada por Cristo Jesus ( $\mathrm{Rm} 5,15.17)$. O confronto autêntico com Adão oferece a possibilidade a Paulo não só de afirmar a eficácia da ação salvífica de Jesus Cristo, mas de dilatar para a dimensão antropológica universal. Se existe uma relevância Universal do primeiro Adão, também Cristo, segundo Adão, possui uma relevância universal. Adão e Cristo são duas figuras iniciadoras e representativas do destino de toda a humanidade. A vocação de todo homem é tornar-se imagem do Adão celeste, Cristo.

\section{Cristo, imagem de Deus}

O livro do Gênesis 1, 27 afirma que o ser humano foi criado à imagem Deus. Esta afirmação foi interpretada à luz de Cristo. Segundo o Novo Testamento a imagem de Deus é o próprio Cristo. Em 2Cor 4, 4, Paulo afirma: ...para os incrédulos, dos quais o deus deste mundo obscureceu a inteligência, a fim de que não vejam brilhar a luz do evangelho da gloria de Cristo, que é a imagem de Deus. Em Cl 1, 15, Paulo afirma: Ele (Cristo) a é a imagem do Deus invisível. O conceito está relacionado a teologia da revelação: Jesus enquanto imagem do Pai o Revela. A idéia de ser humano vem reinterpretada à luz de maneira cristológica. Esta leitura cristológica da imagem de Deus, é feita também pela teologia patrística. Santo Irineu, no segundo século, dizia que na encarnação do Verbo nós visualizamos aquele do qual fomos criado imagem. Santo Atanásio, a partir da criação e do pecado, afirma caber ao Verbo e somente ao Verbo a obra da Encarnação. Diz ele: A seguir, a Escritura indica por que nenhum outro, senão o Verbo de Deus, se devia encarnar: "convinha que aquele, para quem tudo é e por quem tudo é, desejando levar grande número de filhos à gloria, aperfeiçoasse pelo sofrimento o autor da salvação deles. Por ai se indica não caber a outro, mas ao Verbo de Deus, que tinha feito no princípio os homens, reergue-los da corrupção que os atingira ${ }^{5}$. Atanásio, na mesma obra,

\footnotetext{
${ }^{5}$ Santo Atanásio, Sobre a Encarnação do Verbo, (S. C. 18).
} 
faz a ligação do ser humano, criado a Imagem de Deus, e tendo sido esta imagem desfigurada, o Verbo, imagem do Pai, deveria se encarnar para recriar o homem segundo a divina imagem ${ }^{6}$.

\section{A Relação entre Cristologia e Antropologia}

Há uma relação profunda e intrínseca entre Cristologia e antropologia, pois o mistério do ser humano encontra a sua realização plena e definitiva no mistério do Verbo Encarnado. K. Rahner diz que após a Encarnação, a antropologia sempre se há de considerar como cristologia deficiente e a cristologia como fim e fundamento da antropologia, porque em Jesus se revelou historicamente e se encontra de modo inexcedivel o que e quem é o homem. Em vista disso, é evidente que uma protologia adequada não é possível senão sob o aspecto escatológico, isto é, a partir de Cristo ${ }^{7}$. Diz H. Fries: "Razão e meta da criação, Cristo coloca em verdadeira luz a dimensão de revelação da mesma criação. A criação está voltada para Cristo. Ele próprio é a plenitude da criação, a palavra final da palavra criadora, o mais alto desfecho e plenitude da obra criada, sobretudo do homem, que, em Cristo, encontra sua nova e verdadeira imagem. Jesus é assim, o verdadeiro homem, o segundo, e autêntico Adão. Cristo e ninguém mais, é que se aplica o "ecce homo" (cf. 1Cor 15, 21s; 45-49). A imagem deste homem é a daquele que se funda totalmente em Deus. É o que se acha completamente aberto para Deus, é o ouvinte da Palavra, é o que obediente cumpre Sua vontade, é o que ama a Deus sobre todas as coisas e, por isso, se acha ligado aos outros homens em abnegado devotamento e serviço fraterno. Nesta imagem do homem está o fundamento da antropologia. Quanto mais alguém vive em Deus, tanto mais se realiza a si próprio"8.

Na reflexão antropológica de W. Pannenberg a fé cristã apresenta uma contribuição peculiar para a compreensão do homem a partir de Jesus Cristo, aquele que nos revelou a verdadeira face de Deus e o sentido mais radical e profundo do ser humano. Necessita a antropologia de uma fundamentação cristológica?? A cristologia não consiste apenas numa "ilustração da auto-in-

\footnotetext{
${ }^{6}$ Santo Atanásio, Sobre a Encarnação do Verbo, (S. C. 18).

${ }^{7}$ K. RAhner, "Reflexões fundamentais sobre a antropologia e a protologia no conjunto da Teologia”, in Mysterium Salutis, II/2, Editora Vozes, Petrópolis, 1972, p. 17.

${ }^{8}$ H. Fries, "Conceito católico de Revelação", in Mysterium Salutis, I/1, 229.

${ }^{9}$ W. Pannenberg percebe que, a primeira vista, a relação deveria ser determinada de maneira inversa, pois a cristologia em todas as épocas da história, foi influenciada de modo eficaz por diversas formas de auto-compreensão humana e de anseios humanos. Todas estas maneiras de
} 
terpretação do homem em imagens ideais de uma humanidade perfeita, esta aponta e se fundamenta num dado fundamental: a determinação do homem realizada em Jesus, uma vez que ele é o verdadeiro ser humano, tornado possibilidade para todos os outros homens. A cristologia fornece uma significação constitutiva para uma antropologia universal, pois "a história de Jesus como revelação de Cristo tem a oferecer sua contribuição própria e até constitutiva a respeito da questão do homem, [e esta] não se manifesta no fato de ela colocar um inicio completamente novo, mas no de ela transformar - enquanto a assume - a realidade já existente do homem, e por isso também os interrogativos deste a respeito de si mesmo".

Para a fé cristã, "com o aparecimento de Cristo, todo o ser-homem precedente foi substituído por uma forma radicalmente nova de ser-homem: na ressurreição de Jesus contrapôs-se ao primeiro Adão um novo, um segundo Adão, não mais apenas ser vivente, mas espírito vivificante (1Cor 15,45ss)". Em Paulo há duas concepções antropológicas relacionadas a questão da imagem de Deus. A verdadeira imagem de Deus é Cristo, o segundo homem (2Cor 4,4) e somente pelo batismo, que liga a Cristo, os homens tornam-se participantes da semelhança com Deus ( $\mathrm{Rm} \mathrm{8,29;} \mathrm{cf.} \mathrm{Cl} \mathrm{3,10).} \mathrm{A} \mathrm{semelhança}$ com Deus caracteriza, segundo Gn 1,26, o homem na sua condição criatural $(1$ Cor 11,7). A tensão entre estas duas concepções foi resolvida pela teologia cristã primitiva, entendendo Cristo como arquétipo, a "imagem" do qual o primeiro homem foi criado, portanto, criado como imagem de Deus. A relação com o homem novo manifestado em Cristo se apresentou assim de tal sorte que "somente a aparição visível do arquétipo na encarnação conduz a plenitude a imagem de Deus em nós"10.

A concepção cristã do homem como história do primeiro para o segundo Adão dissolve o conceito filosófico de uma natureza humana essencial, invariável no tempo, na historicidade, no movimento da história concreta, pois ela apresenta à luz do evento Cristo, a natureza humana não como algo pronto e invariável, mas como uma realidade aberta a uma determinação e a uma perfeição somente realizada em Jesus Cristo. O homem é assim concebido, como pura abertura para uma determinação ainda irrealizada ${ }^{11}$.

conceber a definição do homem foram expressas cristologicamente. Isto significa que na figura de Jesus, se viu a verdadeira humanidade assim bem encarnada que torna acessível aos outros homens; W. Pannenberg, Le fondement christologique de l'anthopologie chrétienne, Concilium 86 (juin 1973), 88.

${ }^{10}$ Irineu de Lião, Adv. Haer. V, 16,1.

${ }^{11}$ Pannenberg comenta que esta compreensão foi deformada na história da antropologia cristã 
A partir da fé cristã, o homem deve ser entendido como história que aponta para a salvação manifestada em Cristo, e sua situação inicial, natural, como abertura para aquela determinação futura. Isto significa afirmar que com Jesus entrou algo de novo no mundo vital do homem, algo que deu ao ser humano um conteúdo novo e inacessível de outra maneira, e com isto também uma nova finalidade. Porém em que consiste este essencialmente novo, que faz pensar o homem como história em vista deste acontecimento, por ter-se encravado tão profundamente no ser humano do homem? Para Paulo, este essencialmente novo consiste na chegada do segundo Adão, com a vida que supera a morte, manifestada na ressurreição de Jesus. A teologia patrística seguiu essa linha paulina ao afirmar a imortalidade como bem salvífico transmitido por Cristo, e não como característica própria da alma, como afirmava a concepção platônica. Para a patrística, "somente por Cristo abriu-se ao homem a imortalidade" e esta, não só para a alma, mas também para o corpo. Assim, o homem deve ser entendido como história orientada para a vida que apareceu em Cristo.

\section{A Centralidade Cristológica do Pontificado de João Paulo II}

O papa João Paulo II, de saudosa memória desenvolveu o seu pontificado centrado na relação Cristologia-Antropologia. Ele afirmou na Encíclica Redemptor hominis: "O homem contemporâneo chegará a reconhecer que será tanto mais homem quanto mais se abrir a Cristo acreditando no Evangelho". Esta afirmação mostra que somente a partir do mistério de Cristo, o ser humano encontra a sua verdadeira realização. O pontificado de João Paulo II foi profundamente marcado pelo discurso antropológico. Na sua primeira encíclica Redemptor hominis ele reafirma os princípios centrais da antropologia cristã à luz de Gaudium et Spes 22. Diz ele: "E por isto precisamente Cristo Redentor, como já foi dito acima, revela plenamente o homem ao próprio homem. Esta é -se assim é lícito exprimir-se- a dimensão humana do mistério da redenção. Nesta dimensão o homem reencontra a grandeza, a dignidade e o valor próprios da sua humanidade" (Redemptor hominis 10). Na mesma encíclica, ele mostra que todos os caminhos da Igreja levam

por ter sido a situação da humanidade apresentada como "estado original", como situação paradisíaca. A salvação assim era vista como uma restituição da perfeição do estado inicial, perdida por causa do pecado de Adão. Com esta doutrina do estado original, a concepção cristã do homem como abertura para uma determinação já teria sido dada ao primeiro homem. Somente com o abandono da doutrina do estado original que a fecundidade da concepção cristã do homem pôde aparecer: W. PANnEnberg, Le fondement christologique de l'anthopologie chrétienne, Concilium 86 (juin 1973), 88. 
ao homem. No n. 14 ele diz: "O homem, na plena verdade de sua existência, do seu ser pessoal e, ao mesmo tempo, do seu ser comunitário e social-no âmbito da própria família, no âmbito de sociedades e de contextos bem diversos, no âmbito da própria nação, ou povo (e talvez, ainda somente do clã ou da tribo), enfim no âmbito de toda a humanidade- este homem é o primeiro caminho que a Igreja deve percorrer no cumprimento da sua missão: ele é a primeira e fundamental via da Igreja, via traçada pelo próprio Cristo e via que imutavelmente conduz através do mistério da encarnação e da redenção. Esta tônica estará sempre presente nos seus discursos, que vão além das ideologias centrando-se numa perspectiva cristocêntrica e também antropocêntrica. Na perspectiva do seu convite no dia da posse, ele afirmará sempre a centralidade de Cristo, dirá que "o homem não pode compreender a si mesmo profundamente [....] com suas inquietude, incerteza e também fraqueza e pecaminosidade, com a sua vida e morte, sem aproximar-se de Cristo". Daí decorre a missão da Igreja, todos os caminhos da Igreja levam então ao homem, pois mistério do homem só encontra sentido à luz do mistério de Cristo.

\section{Conclusão}

$\mathrm{Na}$ abordagem da questão da salvação nas outras religiões, a teologia Católica e cristã não pode deixar de centrar-se na cristologia, pois há uma relação intrínseca entre cristologia e antropologia, entre criação, encarnação e plenificação. Cristo é aquele no qual tudo foi criado, no mistério da encarnação a criação encontra o seu sentido e ele é a plenitude de toda a criação. Há a mediação de Cristo na criação e uma determinação crística da criação.

A teologia católica deve assumir a provocação do papa João Paulo II, na Dominus Iesus e aprofundar a mediação particitiva de Cristo. Aqui se encontra uma questão que ilumina elementos da própria teologia católica, como também do discurso sobre a salvação dos membros das outras religiões.

Nesta perspectiva, deve-se aprofundar o n. 14 da Declaração Dominus Iesus, onde se propõe o aprofundamento da mediação participativa de Cristo. Diz o texto: "O Concilio Vaticano II, de fato, afirmou que "a Única mediação do Redentor não exclui, antes suscita nas criaturas uma cooperação múltipla, que é participação na fonte única”. Há que aprofundar o conteúdo desta mediação participada, que deve ser todavia regulada pelo princípio da única mediação de Cristo". 


\section{Referências Bibliográficas}

ATANÁSIO, Sobre a Encarnação do Verbo, (S. C. 18).

FRIES, H., "Conceito católico de Revelação". In Mysterium Salutis, I/1. Petrópolis: Vozes, 1972, p, 229.

IRINEU de LIÃO, Adv. Haer. V, 16,1.

MUSSNER, F., "Criação em Cristo”. In: Mysterium Salutis, II/2. Petrópolis: Vozes, 1972, p. 53-56.

PANNENBERG, W., "Le fondement christologique de l'anthopologie chrétienne". In: Concilium 86 (1973), p. 88.

RAHNER, K., "Reflexões fundamentais sobre a antropologia e a protologia no conjunto da Teologia". In: Mysterium Salutis, II/2. Petrópolis: Vozes, 1972, p. 17.

RUIZ de la PENÃ, J. L., Teologia da Criação. São Paulo: Loyola,1989.

\section{Paulo Cezar Costa}

Bispo auxiliar da Arquidiocese de São Sebastião do Rio de Janeiro; Doutor em Teologia pela Pontifícia Universidade Gregoriana de Roma; Membro da Comissão de doutrina da CNBB; Professor do Departamento de Teologia da PUC-Rio; Professor do Instituto Superior de Teologia da Arquidiocese do Rio. 